\title{
The application of sensitivity analysis in hydropower based on grey theory
}

\author{
C Li \& W.S Zhu \& B.X Li \& X Xu \& D.F Zhang \\ Geotechnical and Structural Engineering Research Center, Shandong University, Jinan 250061, \\ China
}

KEYWORD: cavern stability; grey relation analysis; numerical analysis; sensitivity analysis; plastic zone

ABSTRACT: Since the complexity of the structure of rock itself and the current test conditions is relatively simple, combined with uneven quality of test personnel, rock mass mechanics parameters are necessarily inconsistent with the actual situation. Based on grey relation analysis of parameters sensitivity of cavern stability, you can analyze the influence degree of the relative variation of rock mass mechanics parameters on the cavern stability. Taking Dagangshan hydropower Station as an example, considering the rock mechanics parameters elastic modulus, poisson' s ratio, cohesion, angle of internal friction disturbance, using sensitivity analysis method for determining a main building around Dagangshan hydropower plastic zone biggest impact is cohesion, angle of internal friction, followed by elastic modulus, poisson' s ratio. This provides a theory foundation for the future test staff should pay more attention to rock mass' $\mathrm{s}$ cohesion, angle of internal friction in acquiring rock mechanics parameters, ensuring the rock mass' $\mathrm{s}$ accurate cohesion, angle of internal friction, thus indirectly ensure the stability of underground engineering.

\section{INTRODUCTION}

In recent years, the underground tunnels of China's hydropower station projects have emerged in endlessly. And the followed cavern stability[8] problems are also affecting the construction of underground cavern. The main reason is that the complexity of engineering rock mass structure makes the measurement of rock mass mechanics parameters[2] exist inevitable errors. Studying the variability of mechanical parameters, and analyzing its degree of the importance to the stability of surrounding rock in underground cavern. It means that more attention should be paid to highly sensitive target mechanical parameters selectively in the practical engineering, when it is necessary to make the necessary correction based on reliability index, and to gain greater returns under the condition of limited resources, then the useful technical and theoretical support are provided for the development of underground space .

In the reliability sensitivity analysis[4,5] of parameters, Zhu Weishen etc[1] made Laxiwa hydropower station as an example, and did the sensitivity analysis about the influence of joint rock mass parameters to surrounding rock damage area.

Zhang Jixun etc[10] made buried long headrace

tunnel of the JinpingII Hydropower Station as an example, by using the planar nonlinear finite element method, and the sensitivity analysis was carried out concerning the impact of the parameters of surrounding rock for the stability of surrounding rock. Liu Lipeng etc[9] made the sensitivity analysis in terms of the slope stability on the basis of FLAC3D finite difference software and adopted grey relational analysis method. Nie Weiping etc[3] applied the sensitive grey relational analysis method of grey system, the sensitive grey relational analysis was implemented about three dimensional elastic-plastic finite element cavern stability parameter. In this article, the practical engineering, the surrounding rock stability of workshop cavern of Dagangshan hydropower station was researched as object, the method combined laboratory measurement of mechanical parameters with the numerical calculation was adopted, and the sensitive grey relational analysis method was also applied, in addition, emphatically discussed the effect of the changes of mechanical parameters of surrounding rock on the stability of the cavern. 


\section{Getting started}

Dagangshan hydropower station is located on the middle section of Dadu River in Sichuan province, in the Yaan city Shimian county and Wajiao township. Complex geology in engineering area and characteristic of higher levels of stress distribution have brought great difficulties to construction of Dagangshan hydropower station.

Hydropower station diversion system was decorated in the left bank, which consists of power house, transformer house, and surge chamber. These caverns are parallel to each other, the axial direction is NE55 ${ }^{\circ}$, and the vertical depth is from $385 \mathrm{~m}$ to $543 \mathrm{~m}$, while the horizontal buried depth is range $304 \mathrm{~m}$ from $513 \mathrm{~m}$, the total length of power house is $216.48 \mathrm{~m}$, and the excavation span above crane beam is $30.80 \mathrm{~m}$, the biggest excavation height among main generating sets is $73.78 \mathrm{~m}$, and the floor elevation of draft tube is $920.02 \mathrm{~m}$; the main substation room space size is greater than the deputy substation room, and the dimension(length $*$ width * height) is $144 \mathrm{~m} * 18.8$ $\mathrm{m} * 25.60 \mathrm{~m}$; The dimension(length * width * height) of surge chamber is $132.00 \mathrm{~m} * 24.00 \mathrm{~m} *$ $75.08 \mathrm{~m}$, the floor elevation is $920.02 \mathrm{~m}$, as the Fig.1 and Fig.2 show.

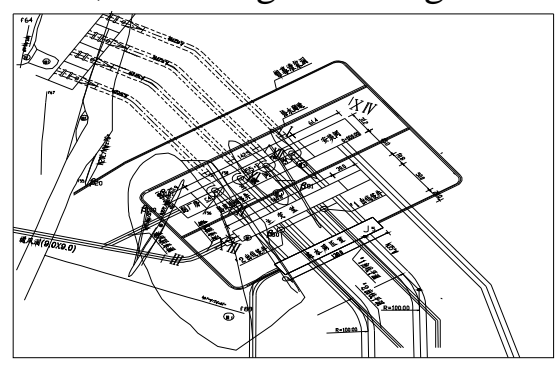

Fig1 The overall layout of the top power buildings

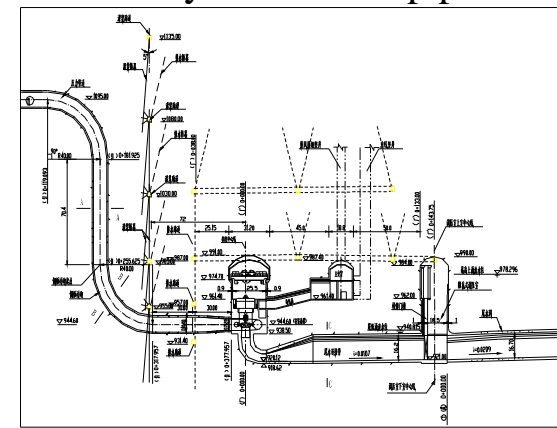

Fig2 Water power generation system (factory) profile

The surrounding rock mass of underground powerhouse is mainly consisting of grey and reddish grained biotite monzonite granite (gamma 24-1), local rock contains green veins. The quality of rock mass of factory is good, mainly composed of massive structure, and the cementing between the rocks is also strong, in addition, around the workshop hole area there are sever large-scale weak structural planes f57, f58, f59 and f60 through the fault, and extended distance is great.

There are some local IV level structure of the weak development faces near the factory. Mainly four groups of fractures developed in the rock mass and the extension length is $3 \mathrm{~m} \sim 5 \mathrm{~m}$, individual of those $>5 \mathrm{~m} \sim 10 \mathrm{~m}$, and the spacing is $0.5 \mathrm{~m} \sim 1 \mathrm{~m}$ in general, all fracture faces are flat coarse and closed, what is more, the steep joint face of group (2)、(3)、(4) almost have many alterations, overall steep dip angle structure plane near SN developed mostly, and the slow crack of local areas from group (5) developed well. According to the adit reveal, the group (4)、 (5)are the main water fractured, and the slow crack of group (5) locally developed into fracture dense zone, hence, it is easy to form shares of running water. Firstly the axial direction protocoled of the power house is $\mathrm{NE} 55^{\circ}$, and the angle between the axial direction and the major principal stress is small, it skews with the steep crack near SN direction. According to the classification of surrounding rock, the surrounding rock of power house, transformer house, and surge chamber mainly is class II 、 III, and the whole rock is stable. The steep and slow slope fracture dense area and diabasic dike fracture zone developed partly, which belong to IV, V class surrounding rock, and are against surrounding rock stability of local hole section, local area of groundwater from seeping out. 
Table 1 Geological structural plane statistics in Dagangshan

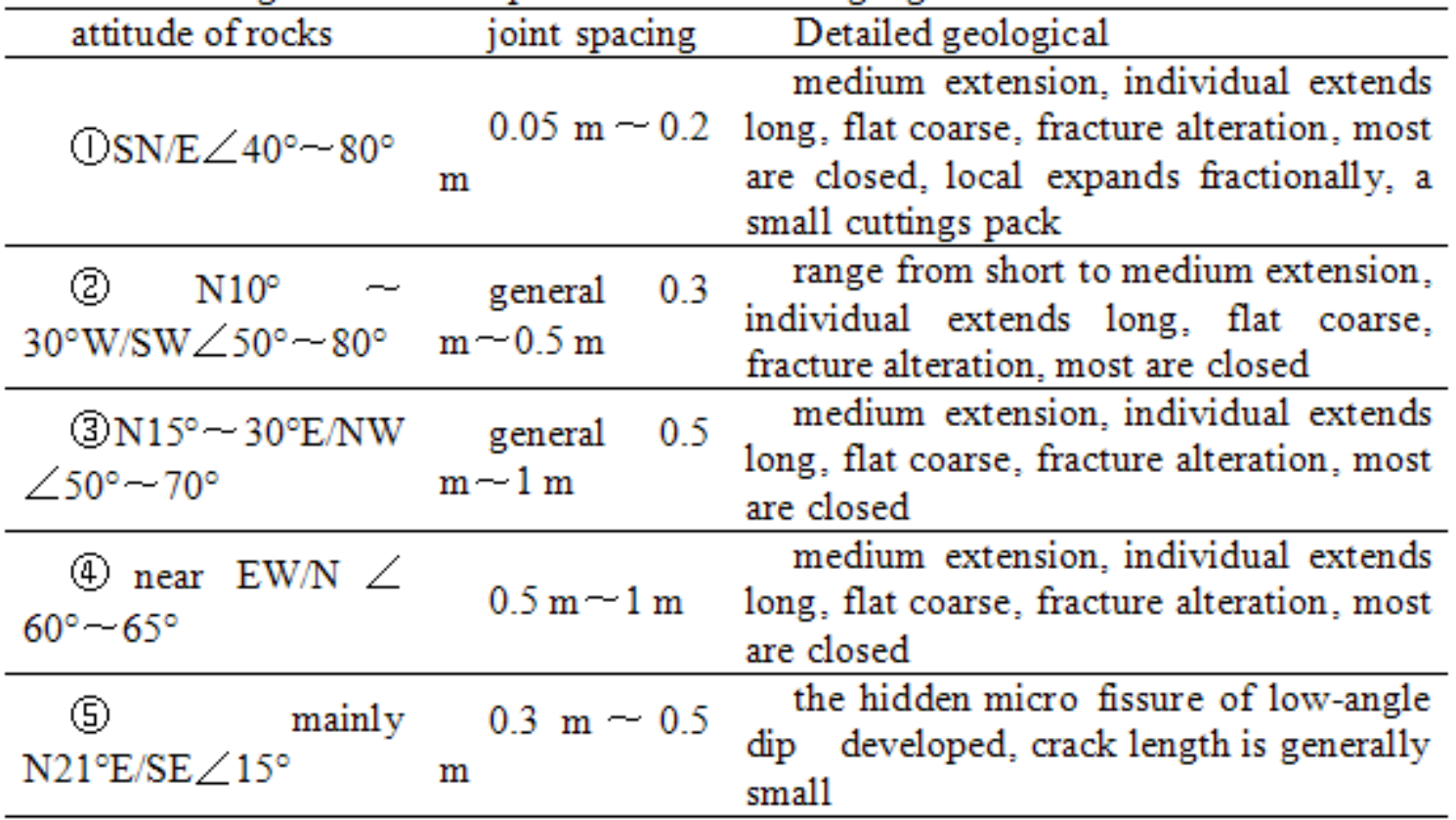

According to engineering geological exploration, combined with the corresponding geotechnical engineering exploration national standards and the particularity of the engineering prospecting design asked to make survey design and take the core to determine the mechanical parameters. The drilling core sample of factory is shown in the following figure 3 , the rock cores were marked as A1-3 and A1-6, and then the Brazilian splitting test was carried on.
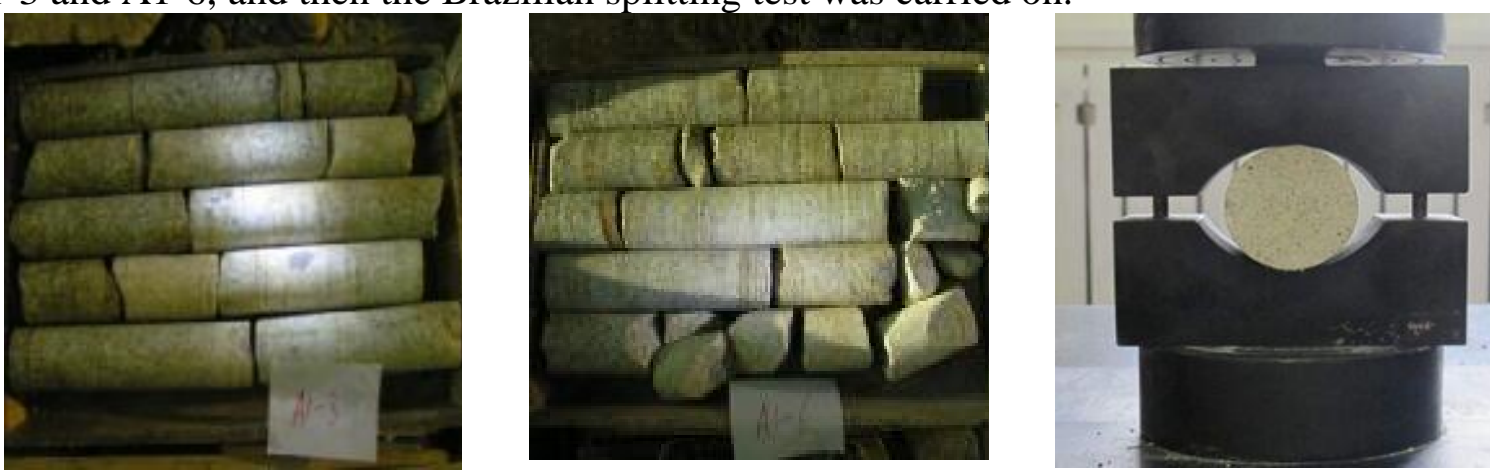

Fig 3 Drill core

Based on the geological exploration report of Dagangshan, Table 2 lists the initial value of rock mechanics parameters.

Table 2 Initial value of mechanical parameters of rock mass P1 and P2

\begin{tabular}{lcccccc}
\hline $\begin{array}{c}\text { surrounding } \\
\text { rock } \begin{array}{c}\text { mass } \\
\text { classification }\end{array}\end{array}$ & $\begin{array}{c}\text { density } \\
(\mathrm{kg} / \mathrm{m} 3)\end{array}$ & $\begin{array}{c}\text { modulus of } \\
\text { deformation } \\
(\mathrm{GPa})\end{array}$ & $\begin{array}{c}\text { friction } \\
\text { angle }\left({ }^{\circ}\right)\end{array}$ & $\begin{array}{c}\text { cohesion } \\
(\mathrm{MPa})\end{array}$ & $\begin{array}{c}\text { poisson's } \\
\text { ration }\end{array}$ & $\begin{array}{c}\text { tensile } \\
\text { strength } \\
(\mathrm{MPa})\end{array}$ \\
\hline II & 2650 & 22.13 & 52.7 & 1.94 & 0.25 & 4.7 \\
\hline III & 2650 & 7.62 & 45.6 & 0.95 & 0.285 & 2.7 \\
\hline IV & 2650 & 1.25 & 38.7 & 0.7 & 0.35 & 1.3 \\
\hline IIIII & 2650 & 14.9 & 49.2 & 1.44 & 0.27 & 3.7 \\
\hline
\end{tabular}

\section{BASIC PRINCIPLES AND METHODS OF GREY CORRELATION ANALYSIS}

Grey theory was first put forward by chinese scholars Deng Zoulong, grey relational analysis is a part of the theory, it can find out correlation degree between the various factors(comparative factors) and the reference factors more accurately with limited data, and the greater the relevance is, the bigger the relevance between the comparative factors and the reference factors. The specific steps of analysis are as follows. 
According to the evaluation purpose to determine the evaluation index system and collect evaluation data.

All influence data matrix A

$$
A=\left[\begin{array}{c}
\mathrm{A}_{1} \\
\mathrm{~A}_{2} \\
\mathrm{M} \\
\mathrm{A}_{\mathrm{m}}
\end{array}\right]=\left[\begin{array}{cccc}
A_{1}(1) & A_{1}(2) & \mathrm{L} & A_{1}(n) \\
A_{2}(1) & A_{2}(2) & \mathrm{L} & A_{2}(n) \\
\mathrm{M} & \mathrm{M} & \mathrm{M} & \mathrm{M} \\
A_{m}(n) & A_{m}(n) & \mathrm{L} & A_{m}(n)
\end{array}\right]
$$

Determine the reference data column

$$
B=\left[\begin{array}{c}
B_{1} \\
B_{2} \\
M \\
B_{m}
\end{array}\right]=\left[\begin{array}{cccc}
B_{1}(1) & B_{1}(2) & L & B_{1}(n) \\
B_{2}(1) & B_{2}(2) & L & B_{2}(n) \\
M & M & M & M \\
B_{m}(1) & B_{m}(2) & L & B_{m}(n)
\end{array}\right]
$$

To quantify the index data without principles

$$
A_{i}=\left[\mathrm{A}_{\mathrm{i}}(\mathrm{j})-\min _{\mathrm{i}}\right] / \max _{\mathrm{i}}-\operatorname{minA}_{\mathrm{i}}(\mathrm{j}) \text {, in which, } \mathrm{i}=(1 \sim \mathrm{m}), \mathrm{j}=(1 \sim \mathrm{n})
$$

At the same time, according to the above method, the reference sequences are also quantified without principles.

Gain the grey relevance

Relevance

$$
A_{i}=\frac{1}{\mathrm{n}} \sum_{\mathrm{j}=1}^{\mathrm{n}} \delta \mathrm{ij}
$$

The range of relevance value is $[0,1]$, and in the incidence degree sequence, if the larger the relevance of influence parameters is, it suggests that the greater the impact of the influence parameters on the performance targets is, and the greater the sensitivity is, otherwise, the less sensitive it is.

\section{CONSTRUCTION OF THE FINITE ELEMENT MODEL OF DAGANGshan}

The simulation model of underground cavern consisted of power house, transformer house, and surge chamber(see Fig.4), and the ANSYS three-dimensional finite element software developed by America ANSYS company was used to construct the model, according to the three-dimensional calculation model range, the model was divided into 495941 elements, in addition, there are eight structural planes in plant range according to the geologic report, so the solid element was adopted to simulate. The displacement boundary condition and the $\mathrm{M}-\mathrm{C}$ criterion was adopted to calculate. The structure occurrence of the factory is shown in Table 4, the three-dimensional model as shown in Fig.5. According to the report provided by exploration unit, the parameter values in model calculation scope are listed in Table 3.

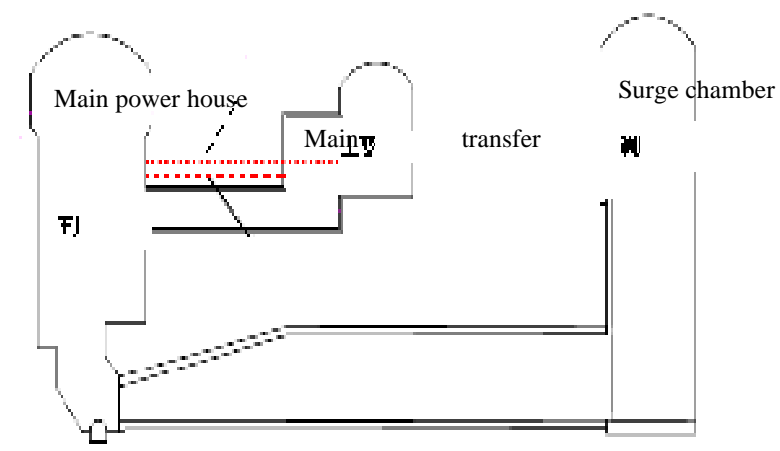

Fig 4 The underground powerhouse layout 
Table 4 Structural plane affecting the stability of underground cavern

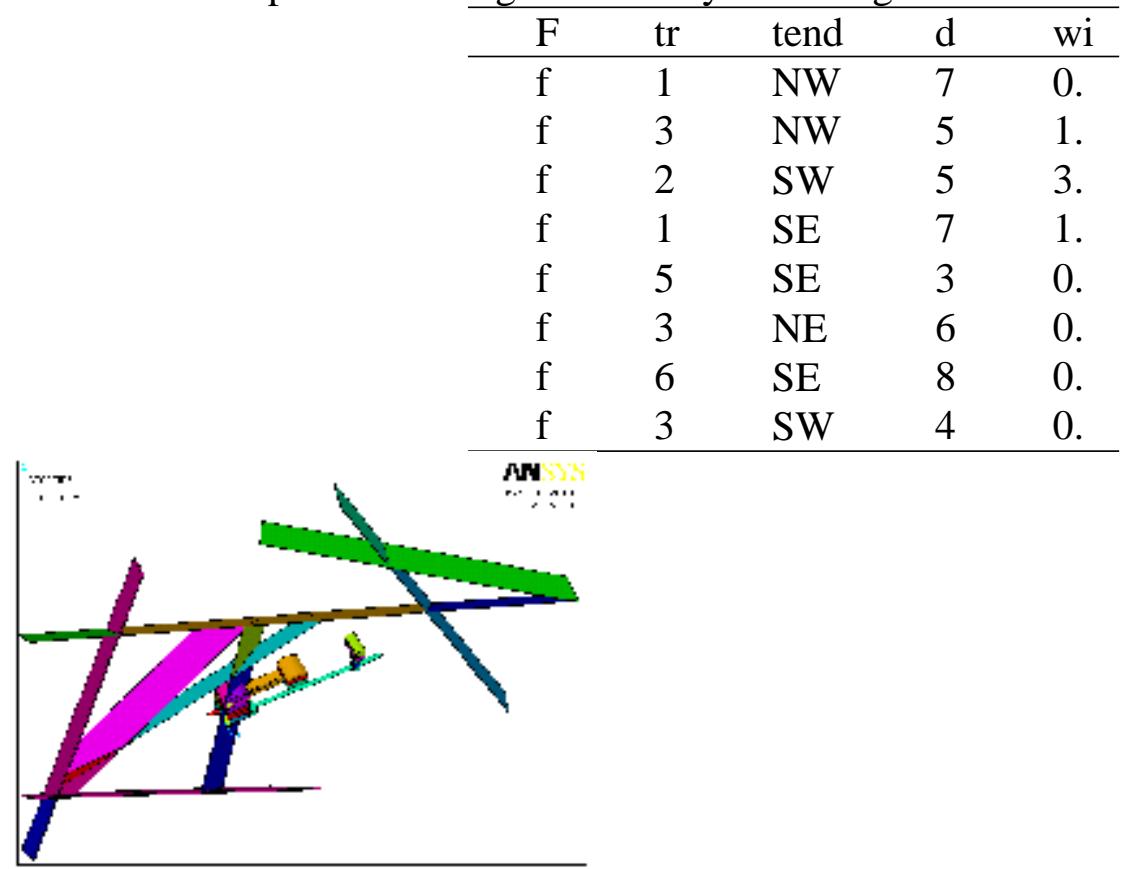

Fig 5 Three dimensional spatial distribution of the structure of the plant

Table 5 The rock mass mechanics parameters in caver

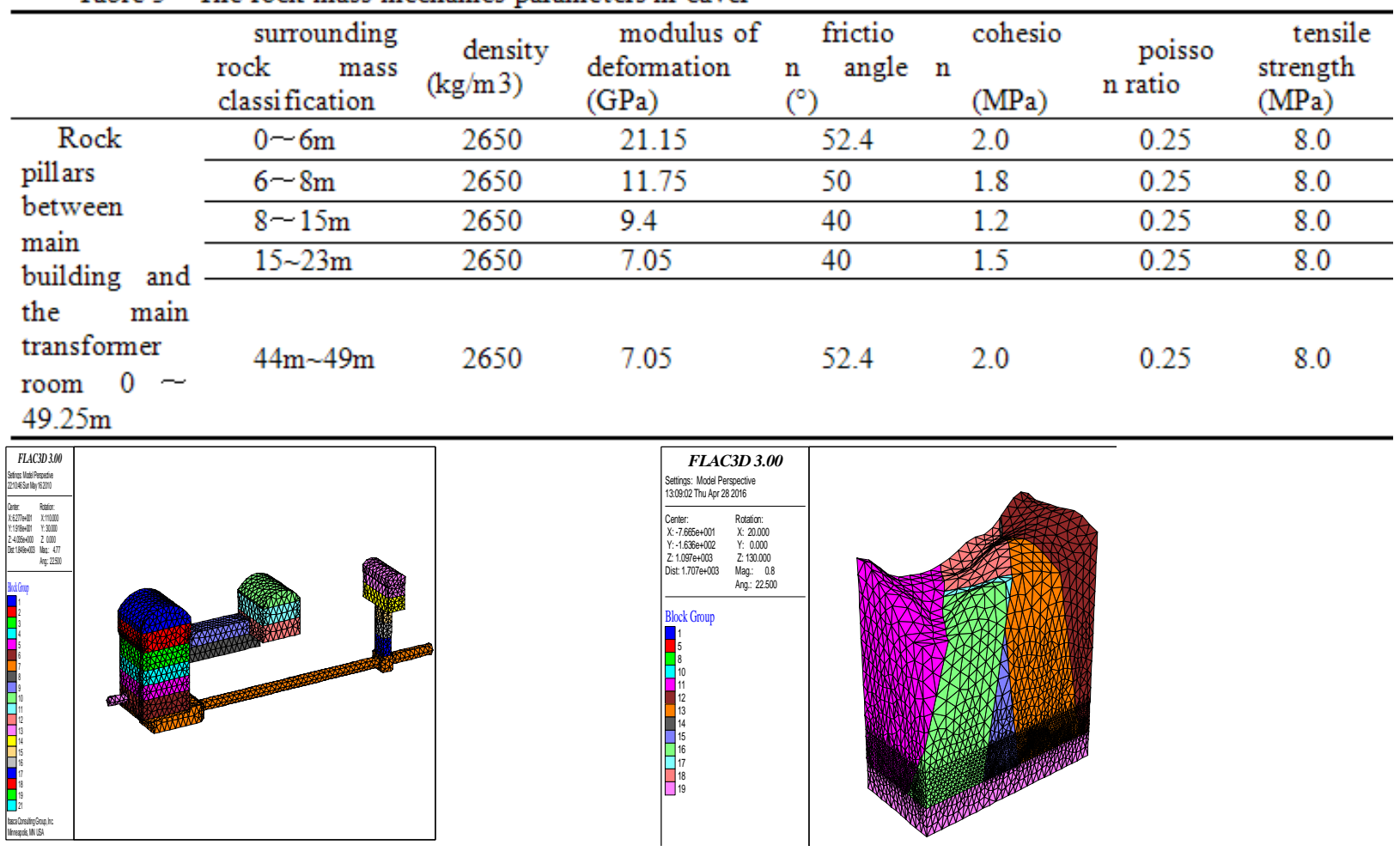

Fig 6 Three dimensional model of Fig 7 Three dimensional model and underground chamber stratigraphic division in cavern

The parameters sensitivity analysis of workshop vault displacement were carried out by changing the values of $\mathrm{E}, \mu, \mathrm{C}, \phi$ of the rock mass in the main plant range, and the fixed variable method was used, the values of E, $\mu, \mathrm{C}, \phi$ were taken turns to change while keeping the other three parameters value remain the same, at this time, E, $\mu, C, \phi$ were as influence matrix, at the same time the area of the plastic zone around the main building was monitored and regarded as reference matrix. Then, using grey relational analysis method can determine the sensitivity of $\mathrm{E}, \mu, \mathrm{C}, \phi$ for the settlement of the cavern displacement. 
Table 3 Impact parameter distribution table

\begin{tabular}{|c|c|c|c|c|c|c|c|}
\hline $\begin{array}{l}\text { reference } \\
\text { value }\end{array}$ & variation range & $\begin{array}{l}\text { reference } \\
\text { value }\end{array}$ & $\begin{array}{l}\text { variation } \\
\text { range }\end{array}$ & reference vahue & $\begin{array}{l}\text { variation } \\
\text { range }\end{array}$ & $\begin{array}{l}\text { reference } \\
\text { value }\end{array}$ & $\begin{array}{l}\text { variation } \\
\text { range }\end{array}$ \\
\hline E0 & $(0.8 \sim 1.1) \mathrm{E} 0$ & $\mu 0$ & $\mu 0^{(0.85 \sim 1.1)}$ & $\mathrm{CO}$ & $\mathrm{C} 0^{(0.85 \sim 1.1)}$ & 90 & $\infty 0^{(0.85 \sim 1.1)}$ \\
\hline
\end{tabular}

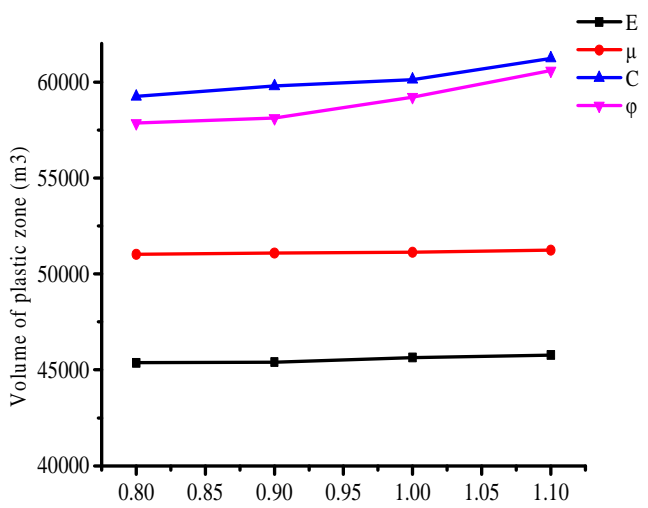

Fig 8 The change curve between the volume of plastic zone and E, $\mu, C, \varphi$

The change of parameter values was selected as comparison matrix, while the corresponding displacement value of arch sedimentation was chosen as reference matrix, and both of them were quantified without principles.

$$
A=\left[\begin{array}{c}
\mathrm{E} \\
\mu \\
\mathrm{C} \\
\varphi
\end{array}\right]=\left[\begin{array}{llll}
0.8 \mathrm{E} & 0.9 \mathrm{E} & 1.0 \mathrm{E} & 1.1 \mathrm{E} \\
0.8 \mu & 0.9 \mu & 1.0 \mu & 1.1 \mu \\
0.8 \mathrm{C} & 0.9 \mathrm{C} & 1.0 \mathrm{C} & 1.1 \mathrm{C} \\
0.8 \varphi & 0.9 \varphi & 1.0 \varphi & 1.1 \varphi
\end{array}\right]
$$

Comparison interval was transformed to relative value:

$$
A^{\prime}=\left[\begin{array}{l}
\mathrm{E}^{\prime} \\
\mu^{\prime} \\
\mathrm{C}^{\prime} \\
\varphi^{\prime}
\end{array}\right]=\left[\begin{array}{llll}
0.00 & 0.33 & 0.67 & 1.00 \\
0.00 & 0.33 & 0.67 & 1.00 \\
0.00 & 0.33 & 0.67 & 1.00 \\
0.00 & 0.33 & 0.67 & 1.00
\end{array}\right]
$$

The reference matrix interval was also transformed to relative value, then matrix $\mathrm{B}$ 'were obtained.

$$
B^{\prime}=\left[\begin{array}{llll}
0.0000 & 0.6562 & 0.4429 & 1.0000 \\
1.0000 & 0.4723 & 0.5533 & 0.0000 \\
0.0000 & 0.6659 & 0.8834 & 1.0000 \\
0.0000 & 0.4875 & 0.6832 & 1.0000
\end{array}\right]
$$

The size matrix of plastic zone around the power house was disposed by dimensionless processing, the resolution coefficient was $\zeta=0.5$, then the grey relational coefficient matrix $\gamma$ of plastic zone size under all kinds of conditions were calculated, and the average value was taken to gain the incidence degree sequence $\mathrm{A}$ under each operating condition:

$$
A=\left\{\begin{array}{llll}
0.5248 & 0.5064 & 0.6373 & 0.5427
\end{array}\right\}
$$

Based on the above incidence degree sequence of plastic zone size of main power house, the impact of different parameter to plastic zone size of main power house was listed from big to small order: $\mathrm{C}, \varphi, \mathrm{E}, \mu$, and the sensitive degree of $\mathrm{C}, \varphi$ was more apparent. It showed that the grey relation analysis can overcome the limitations caused by inconsistency of each parameter dimension in the conventional sensitivity analysis. That makes the sensitive degree of impact of influence parameters to plastic zone volume of the main power house comparable, and provides a new thought for the future analysis of cavern surrounding rock stability, in addition, that has pointed out the direction 
for laboratory test parameter determination, hence, higher requirements are put forward for the test of internal friction angle $\varphi$ and cohesion $c$.

\section{CONCLUSION}

(1) Normally, the estimation of the range of the plastic zone caused by underground excavation plays a vital role in optimizing excavation way and improving the supporting means. Grey correlation analysis is good for confirming the influence of change of mechanical parameters measured by laboratory test on the plastic zone range caused by underground excavation, thus the key mechanical parameters are found out to providing strong guarantee for the safety of the underground engineering.

(2) Taking the power plant of Dagangshan hydropower station as an example, three-dimensional finite element model is established by using ANSYS, and the numerical simulation study was carried out through using the finite difference software FLAC 3d, the key part of the underground cavern - plastic zone extended range of main workshop was selected as monitoring object, and to analyze what influence the disturbance of mechanical parameters has on plastic deformation. When using conventional sensitivity analysis method, the inconsistent dimension of influence parameters lead research methods having great limitations, while using the grey correlation analysis can overcome the shortage of the conventional sensitivity analysis method, and the results show that the influence degree of $\mathrm{E}, \mu, \mathrm{C}, \varphi$ on the plastic zone size around the main factory building after excavation is listed from big to small order: $\mathrm{C}, \varphi, \mathrm{E}, \mu$ and the sensitive degree is more obvious.

(3) This article only made sensitivity grey relational analysis on several main factors to the stability of underground engineering under the condition of the single factor, without considering the correlation between the impact factors. In the actual situation, changes of all the factors also cause corresponding changes of other factors, that is the correlation between rock mass mechanics parameters. Therefore, for under the coupled action of various factors of the underground engineering stability still need further research.

\section{ACKNOWLEDGEMENTS}

The work is supported by the National Natural Science Foundation of China 51279095. W.S. Zhu is the corresponding author.

\section{REFERENCES}

Zhu Weishen, Zhang Guagn. Sinsitivity analysis of influence of jointed rock parameters on damaged zone of surrounding rock[J]. Underground Space, 1994,14(1):10 - 15.

Huang Shuling, Feng Xiating, Zhang Chuanqing. Study of method of comprehensive evaluation for parameters of comstitutive model of rock mass. Chinese Journal of Rock Mechanics and Engineering[J], 2008(S1)

Nie Weiping, Xu Weiya Zhou Xianqi . Grey relation analysis of parmeter sensitivity of cavern stability based on 3D elastoplastic finite elements. Chinese Journal of Rock Mechanics and Engineering[J], 2009(S2)

Muriel Gevrey,Ioannis Dimopoulos,Sovan Lek. Two-way interaction of input variables in the sensitivity analysis of neural network models[J]. Ecological Modelling. 2005 (1)

M. Hohenbichler, R. Rackwitz. Sensitivity and importance measures in structural reliability[J]. Civil Engineering and Environmental Systems . 1986 (4)

Lin Dan, Lu Pengfei, Li Fangping. Safety management in engineering construction of Dagangshan Hydropower Station[J]. Yangtze River ,2014(22).

Wang Fenglian, Liu Feng. Safety monitoring and management of Dagangshan Hydropower Station in construction period. Yangtze River, 2014(22). 
Zhou Weiyuan. Advanced rock mechanics[M]. Beijing: Water Resources and Electric Power Press, 1990: 100-150.(in Chinese)

Liu Lipeng, Yu Hongjie, Chen Qi, et al. Sensibility analysis of soil slope stability on mechanical and geometrical parameter[J]. Geotechnical Engineering Technique, 2008, 22(3): 123-126.(in Chinese).

Zhang Jixun, Jiang Hongdao, Ren Xu-ua. Sensitivity Analysis of Mechanical Parameters Influencing Stabilization of Surrounding Rocks of Tunnel. Journal of Mining \& Safety Engineering, 200. 